\title{
Current perspective of COVID-19 spread across South Korea: exploratory data analysis and containment of the pandemic
}

\author{
Amarpreet Singh Arora ${ }^{1}$ (D) Himadri Rajput ${ }^{2} \cdot$ Rahil Changotra $^{2}$
}

Received: 10 June 2020 / Accepted: 11 July 2020 / Published online: 8 August 2020

(c) Springer Nature B.V. 2020

\begin{abstract}
The outbreak of severe acute respiratory syndrome coronavirus 2 is regarded as a highly contagious disease that has challenged the healthcare systems worldwide with confirmed cases approaching 12 million and more than 50,000 deaths. Considering the worldwide cases of novel coronavirus disease (COVID-19), it remains a pandemic and the vaccines and therapeutic agents have yet to be developed to stop the spread of this outbreak. Due to the unavailability of specific treatment for the COVID-19, it can be viewed that the risk of cluster infection will continue to be present within the intermittent and small-scale outbreaks. Though the COVID-19 has been identified as a communicable disease, the preventive measures and response policies in South Korea are effectively serving the purpose and gained the confidence to overcome the COVID-19 crisis. This paper includes the exploratory data analysis of COVID-19 cases in South Korea till July 8, 2020. South Korea has reported the lowest death rate with the majority of the deaths, associated with persons with underlying health conditions or elderly infected individuals. Currently the infected patients (total 989) remaining in South Korea are mild cases owing to its robust health care system and quarantine inspection procedures followed by the Ministry of Health and Welfare of South Korea to flatten the COVID-19 curve. Although the COVID-19 countermeasures taken by the South Korean government may not be conclusive or universal for all, but its exemplary approach to tackle COVID-19 can aid countries across the globe to strengthen their response system for the future outbreak of such an infectious disease.
\end{abstract}

Keywords COVID-19 $\cdot$ Coronavirus $\cdot$ South korea $\cdot$ Pandemic $\cdot$ Quarantine inspection procedures (QIPs)

Electronic supplementary material The online version of this article (https://doi.org/10.1007/s1066 8-020-00883-y) contains supplementary material, which is available to authorized users.

Amarpreet Singh Arora

amarpreet.amar007@gmail.com

$\checkmark$ Rahil Changotra

changotrarahil@gamil.com

1 School of Chemical Engineering, Yeungnam University, Gyeongsan 38541, South Korea

2 School of Energy and Environment, Thapar Institute of Engineering and Technology,

Patiala 147004, India 


$\begin{array}{ll}\text { Abbreviations } & \\ \text { CBS } & \text { Cellular broadcasting service } \\ \text { GMT } & \text { Greenwich mean time } \\ \text { ICT } & \text { Information and communication technologies } \\ \text { KCDC } & \text { Korea centers for disease control and prevention } \\ \text { MERS } & \text { Middle East respiratory syndrome } \\ \text { QIP } & \text { Quarantine inspection procedures } \\ \text { SARS } & \text { Severe acute respiratory syndrome } \\ \text { SARS-CoV-2 } & \text { Severe acute respiratory syndrome coronavirus 2 } \\ \text { WHO } & \text { World Health Organization }\end{array}$

\section{Introduction}

In December 2019, the Wuhan city of Hubei province in China became the epicenter of an outbreak of local pneumonia in some patients with an unknown cause (Bherwani et al. 2020; Gautam 2020). By January 7, 2020, the Chinese research community isolated a novel virus, severe acute respiratory syndrome coronavirus 2 (SARS-CoV-2), from the virus-infected pneumonia patients (Phelan et al. 2020; Gorbalenya et al. 2020). On January 30, 2020, World Health Organization (WHO) declared the SARS-CoV-2 epidemic a Public Health Emergency of International Concern, which was later designated as a COVID-19 in February 2020 (Muhammad et al. 2020; Gautam and Hens 2020a, b; WHO 2020b). Although the outbreak is plausible to be associated with the large seafood market which has triggered a zoonotic transmission event, but soon it became clear that an efficient human-to-human transmission is also taking place ( $\mathrm{Li}$ et al. 2020; Wu et al. 2020; Sarkodie and Owusu 2020). Due to the potential of COVID-19 to generate widespread outbreaks in confined settings and cross border following the mobility of human patterns, it was regarded as a pandemic by the WHO on March 11, 2020 (Cucinotta and Vanelli 2020).

Coronavirus is a current novel and highly infectious contagion disease that belongs to the family of "Nidovirus" which includes "Roiniviridae," "Artieviridae" and "Coronavirdae" family, causing respiratory illness in humans from the common cold to more severe diseases such as Severe Acute Respiratory Syndrome (SARS) and Middle East Respiratory Syndrome (MERS) (De Wit et al. 2016; Gautam and Hens 2020a). Coronavirus is enveloped positive-sense RNA virus mainly comprising of almost 30,000 nucleotides in its genome, and its replication and transcription are dependent on the replicase gene which encodes two overlapping polyproteins, ppla and pplab (Zhou et al. 2020a, b). The diameter of coronavirus ranges from 60 to $140 \mathrm{~nm}$ with club-shaped spikes on its surface and making a crown-like structure as evident from an electron microscopy, hence the name given coronavirus (Richman et al. 2016). Coronavirus is a "communicable" disease and its spread all over the world is entirely associated with human-to-human transmission rather than transmission through the air (Wang et al. 2020a, b). The transmission of COVID-19 through airborne spread has not been reported yet and it is not believed to be the source of major transmission as per the evidence (WHO, 2020a). Due to its small size (about 0.1 micron), it can enter into the body via droplets from mouth or nose during close and unprotected contact between an infector and infectee. It has also been observed that coronavirus infected people generally develop symptoms and signs, including mild respiratory illness, fever, dry cough, and tiredness, with a mean incubation period of 5 to 6 days which can also range up to 1 to 14 days (WHO 2020b). Predominantly, the presentation of 
disease can also range from asymptomatic (with no symptoms) to severe pneumonia, and even death (WHO 2020a). Recent studies showed that the number of infected individuals with the novel COVOD-19 may get double every 7 days and each person could spread this virus to 2.2 to 3.58 persons on an average (Chan et al. 2020). Additionally, the individuals $\geq 60$ years of age and individual with chronic underlying health conditions are in a greater risk of being infected with COVID-19 in comparison to the children who might have less probability to get infected or, if so, these children may show mild symptoms or may have asymptomatic infection (Li et al. 2020; Sun et al. 2020). Besides, cleaning surfaces with an alcohol-based disinfectant is also important to practice to stop the spread as COVID-19 can survive on surfaces such as copper (up to $4 \mathrm{~h}$ ), plastic and stainless steel (up to $72 \mathrm{~h}$ ), and cardboard (up to $24 \mathrm{~h}$ ) (WHO 2020b). Some of the countries have adopted the early isolation of infected patients and quarantine policies to prevent the transmission from the travelers who have returned from the COVID-19 infected countries (Hellewell et al. 2020). Practicing frequent hand hygiene (with alcohol-based gel or sanitizer), maintaining respiratory hygiene, and a physical distance of at least $1 \mathrm{~m}$ ( $3 \mathrm{feet})$ is the best possible way to protect yourself and others from the novel COVID-19 (WHO 2020a). In addition, staying in home quarantine and seeking medical care early if person is allied with the acute symptoms fever, cough, or difficulty breathing, not going outside unnecessarily, avoid touching your eyes, nose or mouth, avoid eating raw meat and unnecessary contact with wild animals, etc. are some other precautionary measure for protection against the coronavirus disease. Nevertheless, a clear representation of the epidemiology of this novel coronavirus and vaccination is still being elucidated (Zhou et al. 2020c).

With the two months of the outbreak, the pandemic spread throughout the world at an alarming speed. As of March 1, 2020, a total of 87,137 confirmed cases and 2997 deaths had been reported globally by the WHO (WHO 2020a), and 58 countries were affected (WHO 2020a). While the cases continue to decline in China, the COVID-19 cases have been reported in more than 100 countries outside of China, including South Korea, Iran, Italy, Japan, France, and Germany by the end of March 2020 (WHO 2020c; Shim et al. 2020; Gautam and Trivedi 2020). The first case in South Korea was reported on January 20,2020 , followed by a rapid increase in the number of cases in subsequent days (Shim et al. 2020). In particular, South Korea quickly became the hardest-hit country affected by the COVID-19 virus, with a steady increase in the number of cases over the month of February 2020. By the end of March 2020, South Korea was successfully able to control the outbreak of the novel COVID-19, and since its peak on March 11, 2020, the daily number of cases has been decreasing. This paper analyzes the trend and data of COVID-19 on certain criteria using "Exploratory Data Analysis." It is a revelatory step to any kind of analysis based on the date sets. In this paper, we reviewed the COVID-19 spread in South Korea with time by considering the different factors during the analysis. This will also enable us to know how South Korea managed to flatten the curve of COVID-19 cases with time.

\section{COVID-19 South Korea's data analysis}

Current and widespread outbreak of novel coronavirus motivates to perform Exploratory Data Analysis (EDA) on the datasets, which was collected from the different sources such as, Korea Centers for Disease Control and Prevention (KCDC, South Korea 2020), the Ministry of Health and Welfare of South Korea (MOHW, South Korea 2020), John Hopkins GitHub repository (JHGR, USA 2020) and Coronavirus Worldometer (Worldometer 
2020). The data was used to analyze the trend and spread pattern of COVID-19 cases in South Korea and compared with a pattern of cases in the most affected countries in the world. The data collected, organized, and processed in the form of graphical representation for the better visualization of results using OriginPro 2016 software (Version 9.3.226, OriginLab Corporation, USA). The total number of confirmed cases, active cases, deaths, and recovered cases as of July 8, 2020 (05:00 GMT), as well as the fatality rate distribution by province-wise was also presented.

\subsection{COVID-19 Spread in South Korea over time}

From the first detected patient on January 20, 2020, to March 1, 2020, when the third patient was reported, confirmed cases were mostly inbound travelers from overseas and their contacts. Following February 18, an exponential surge with a short period was observed, starting with cluster infections mainly related to the Shincheonji Church and Cheongdo Daenam Hospital in Daegu city or South Korea. At that time, South Korea was on the verge of facing a continued surge in the COVID-19 outbreak with new confirmed cases per day amounting to 909 and total cases under isolated treatment at 7470 (MOHW, South Korea). However, the situation has been successfully contained as of now with new confirmed cases per day reduced to a single digit. Figure 1 shows the trend of confirmed, recovered, active and deceased cases of COVID-19 in South Korea till July 8, 2020 (GMT 05:00).

As of July 8, 2020, the total number of confirmed cases in South Korea reported to be 13,244 , with the largest cluster of infected patients from Daegu and Gyeongsangbuk-do accounting for $62.8 \%$ of the total cases. According to the MOHW, among the total cases of 10,806 as on May 5, 2020, females account for $40.5 \%$ and males for $59.5 \%$ (Fig. 2a). Figure $2 \mathrm{~b}$ shows the age distribution of infected persons. The number of deceased reaches 255 with $92.2 \%$ of the deaths from the age group of $\geq 60$ and a fatality rate of $2.36 \%$. The

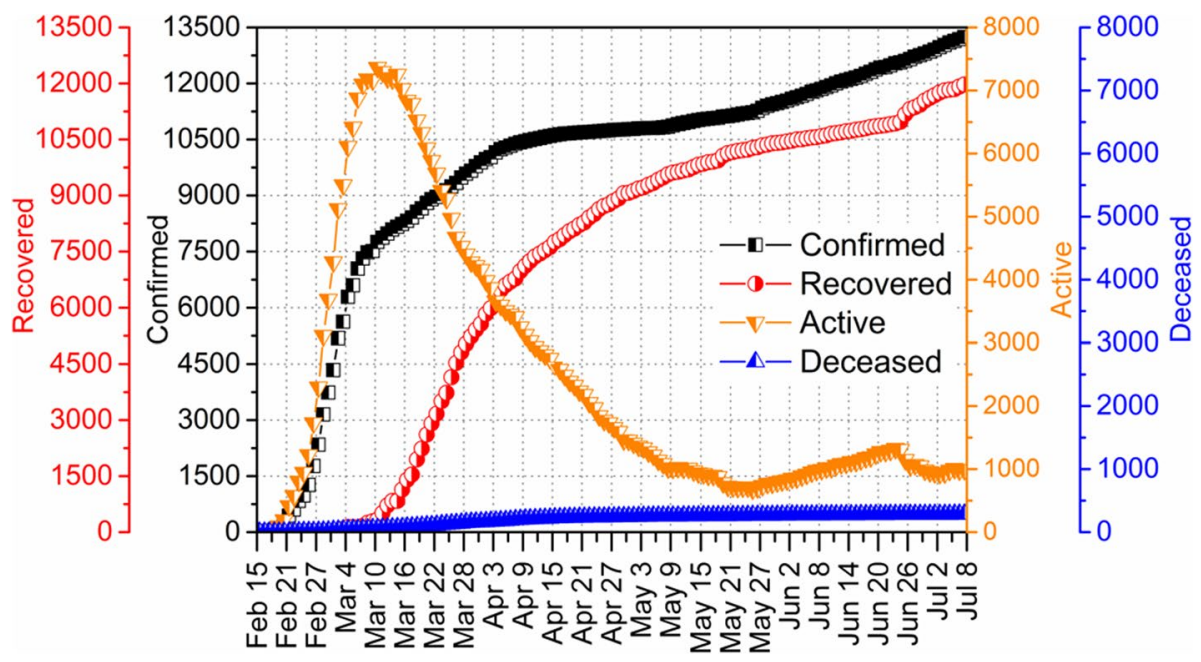

Fig. 1 Trend of COVID-19 in South Korea over time as of July 8, 2020. (Source: MOHW, South Korea and John Hopkins GitHub repository, USA) 

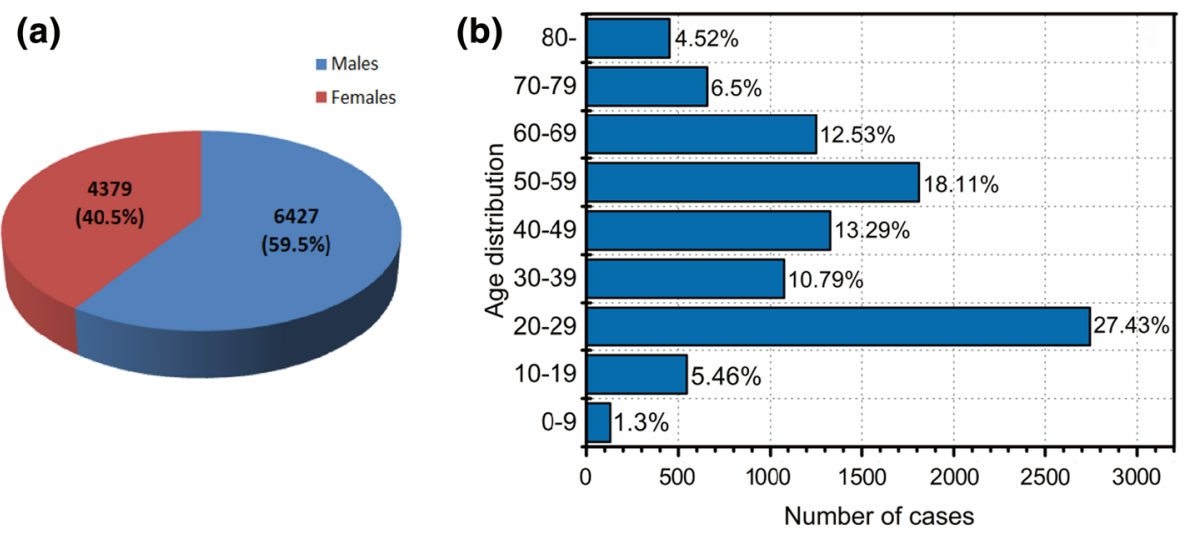

Fig. 2 a Gender-wise cases and b age-wise distribution of COVID-19 in South Korea as of May 5, 2020. (Source: MOHW, South Korea)

average reproduction number of COVID-19 in South Korea was estimated to be 1.5 (Shim et al. 2020).

\subsection{History of imported cases of COVID-19 spread in South Korea}

As of July 8, 2020, there were 1714 of total confirmed cases that had a travel history to different countries. Among them, the USA and Europe together contribute to more than $65.2 \%$ of the total confirmed cases in South Korea as shown in Fig. S2 (supplementary material). Out of the 1714 cases, 1286 (75.1\%) cases were of Korean nationality and 428 $(24.9 \%)$ cases were of foreign nationality.

\subsection{COVID-19 spread in South Korea versus other countries}

When the COVID-19 started spreading across the globe, the initial phase saw South Korea becoming the second most affected country after China (the epicenter of the outbreak). But soon within a span of 2-3 weeks, South Korea managed to control this virus from spreading through its rigorous and effective approach. As of now on July 8, 2020 as shown in Fig. 3, South Korea has witnessed a total of $0.11 \%$ of the COVID-19 cases being reported worldwide, with USA reporting one-fourth of the total number of cases. The number of causalities stands at $0.05 \%$, attributing to the advanced health care system of South Korea. The world is now witnessing the biggest pandemic, with the total death exceeding 550,000 till date. As of July 8, 2020, the total confirmed, deceased, recovered and active cases of COVID-19 were 11,954,944, 546,720, 6,846,897, and 4,206,920, respectively. Table S1 (supplementary material) provides detailed information on the COVID-19 cases around the world with USA and Europe being affected the most in terms of causalities and the number of infected patients.

Compared to the worst hit countries with COVDD-19, South Korea has reported the lowest mortality rate of 2.2, when compared to USA, UK, Spain, Mexico, and Italy with mortality rate of 4.4, 15.5, 11.3, 11.9, and 14.4, respectively (MOHW, South Korea). Thus, the mortality per lakh population in India is 6 deaths per 1 million populations, which is 


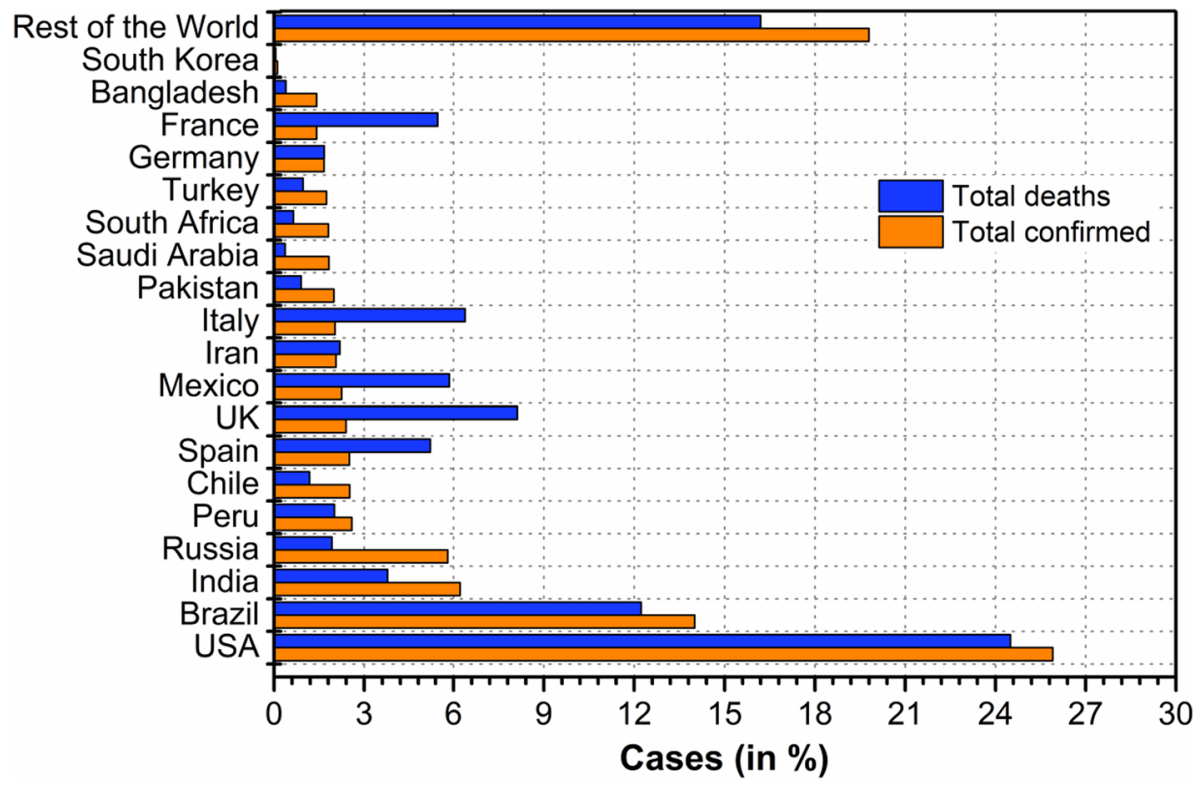

Fig. 3 Comparison of confirmed COVID-19 cases and deaths in South Korea versus other countries. (Source: MOHW, South Korea, As of July 8, 2020, GMT 05:00)

lowest in comparison to the global case mortality rate of 69.7 deaths per 1 million populations (MOHW, South Korea). The relatively low death rate, in terms of case mortality rate, signifies timely clinical management and identification of the COVID-19 cases in South Korea.

\subsection{Testing of COVID-19 in South Korea}

Owing to its early detection and testing capabilities which included extensive use of ICTs and drive-thru testing stations, South Korea was able to contain the spread of this deadly contagion. South Korea is capable of conducting 23,000 diagnostic tests per day, and almost a total of 1,359,735 tests have been conducted until July 8, 2020 (05:00 GMT). Besides, the healthcare professionals in South Korea were allowed to conduct a COVID19 diagnostic test on any suspected individual without any charge. The efforts made by the South Korean Government for carrying the extensive and free of charge diagnosis of COVID-19 was key to minimize the outspread and damage of this virus at an early stage. As of April 27, there are 347 of National Safe Hospitals designed by the government to provide the services for non-respiratory patients and ensuring the safety of general patients. Table S2 (supplementary information) provides the detail of the total numbers to tests conducted, in progress, and the concluded results.

\subsection{Province wise spread of COVID-19 in South Korea}

As of July 8, 2020 the total number of confirmed cases stands at 13,244, which is concentrated mainly in Daegu and Gyeongsangbuk-do province (62.8\% of all confirmed cases) 
and the specific religious sector (Shincheonji) as the major epidemiological link (47\%). Figure 4 provides the province wise data related to the spread of COVID-19 in South Korea. Table S3 (supplementary information) provides the province wise detail on the total number of confirmed and active cases along with the recovered and deceased patients. The death toll in South Korea stands at 285 to date with Daegu having the largest share of causalities of 189 deceased.

\section{South Korea's model response and flattening of its COVID-19 curve}

The world is facing an unprecedented economic, social, and political crisis with the spread of COVID-19. Global leaders and experts regard this pandemic as "the gravest challenge since World War II." South Korea too is no exception in this global pandemic. South Korea had a surge of COVID-19 outbreak and virus started spreading at the local and community level since the $31^{\text {st }}$ patient linked to Shincheonji Church was reported. The number of new coronavirus cases increased exponentially peaking at 909 new infections on February 29. But since then, new cases have dropped significantly. South Korea is being applauded worldwide for being able to successfully flatten the curve on COVID-19 in only 20 days without enforcing extreme draconian measures that restrict the freedom and movement of people. To begin with, South Korea adopted its rigorous quarantine measures for incoming passengers from abroad (both symptomatic and asymptomatic). Figure 5 and 6 provide

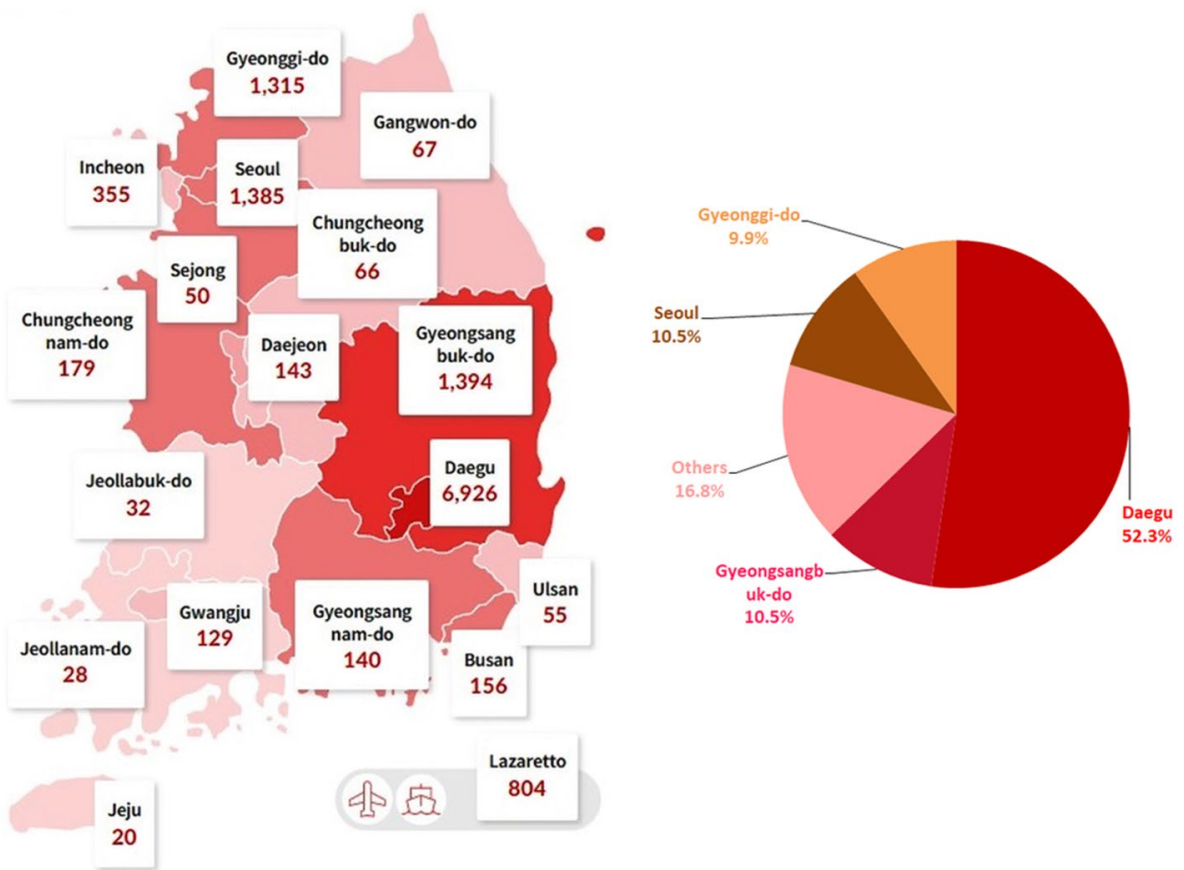

Fig. 4 Province wise spread of COVID-19 in South Korea. (Source: MOHW, South Korea, As of July 8, 2020 (05:00 GMT)) 


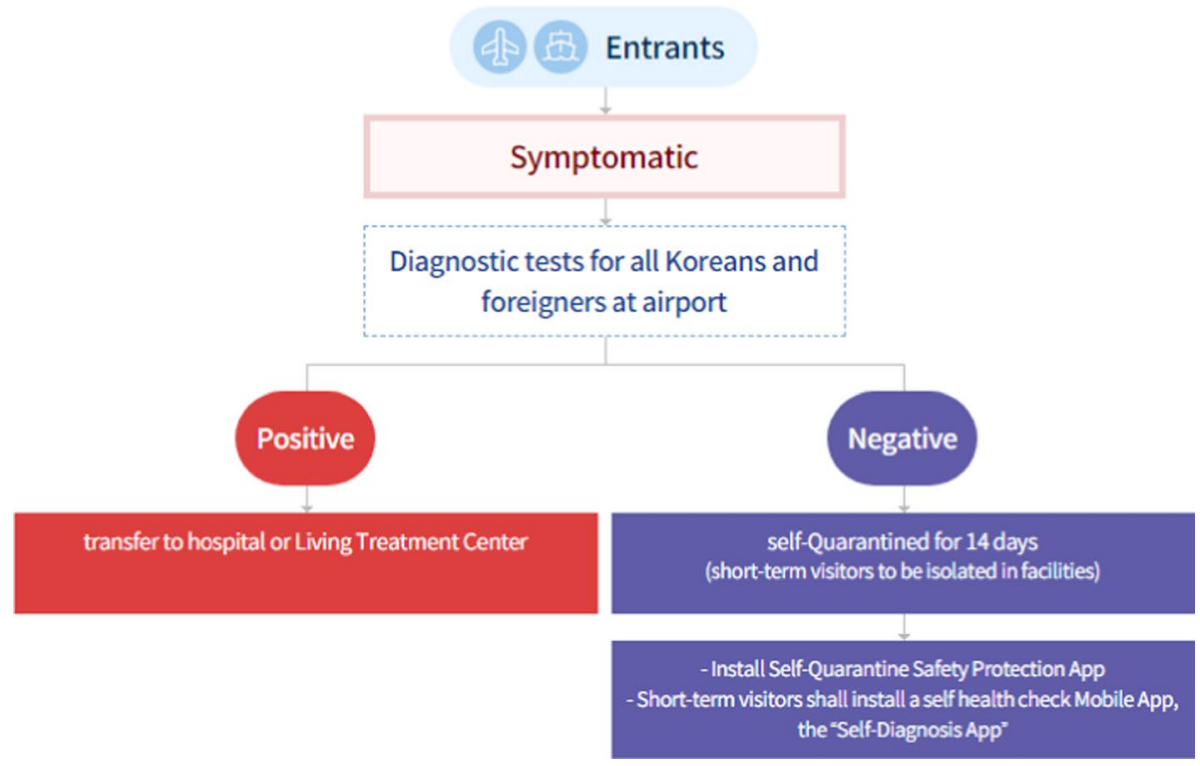

Fig. 5 Flowchart of quarantine inspection procedures for incoming passengers from abroad (from 00:00, April 1)-Symptomatic. (Source: MOHW, South Korea)

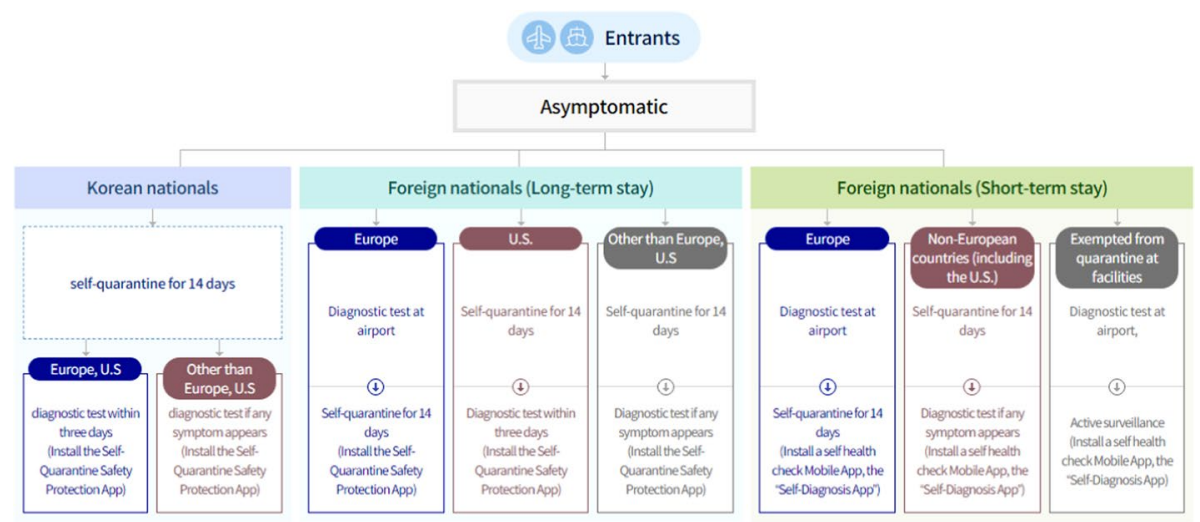

Fig. 6 Flowchart of quarantine inspection procedures for incoming passengers from abroad (from 00:00, April 1)_Asymptomatic. (Source: MOHW, South Korea)

details on the Quarantine Inspection Procedures (QIP) adopted by South Korea for symptomatic and asymptomatic individuals, respectively.

One of the key aspects which played a significant role in South Korea's effective response was its use of ICTs and the state-of-art devices and applications including, Self-Isolation Safety Protection App, Self-Diagnosis App and Epidemiological Investigation Support System which were able to tract the routes of confirmed individuals. Mobile devices, CCTV recordings and credit card usage data were used extensively for contact tracing to boost early testing. Advanced ICTs were particularly useful in spreading key 
emergency information on the novel virus and help to maintain extensive "social distancing." The testing results and latest information on COVID-19 was made available via national and local government websites. Culturally and legally, South Korea is more tolerant of personal data-sharing, and its success has been heavily dependent on its citizens that followed the government guidelines and took responsibility on themselves to self-quarantine in case of suspected illness. The government provided free smartphone apps indicating infection hotspots along with text alerts on testing. Municipalities throughout South Korea made every effort into curbing the contagion as they used the Cellular Broadcasting Service (CBS) to inform the public of the movement paths taken by confirmed patients and other related information. Residents who received COVID-19 emergency texts can quickly check if they have been anywhere that overlaps with the movement of a confirmed patient, allowing them to get tested quickly if necessary. This formed a strong basis for South Korea's early detection and testing capabilities. Figure S2 (supplementary material) shows one such website providing the travel history of the confirmed cases. The image shows the track of COVID-19 patient at a particular location in South Korea using government data available online.

Besides, a walk-thru testing station named K-Walk-Thru testing facilities was adopted by South Korea for the first time in the world to safely and quickly collect the samples of COVID-19 with minimal contact. Since the 2015 outbreak of the Middle East Respiratory Syndrome (MERS), South Korea has learned key aspects, remained vigilant, and continued to refine its response system to better address potential outbreaks of large-scale epidemics, supporting hospitals to set up negative pressure rooms in 2018. The swift actions South Korea has lately taken against COVID-19, including its innovative "drive-thru" testing stations that help minimize the risk of cross infections at the testing centers while maximizing daily testing capacity amid fast rates of new cases, have received international attention and commendations. In addition, the government efficaciously explored various ways to balance the demand and supply of infection control supplies such as hand sanitizers and face masks from the early stage of the outbreak.

\section{Future prospects and conclusion}

South Korea's success with widespread testing and its approach to slowing the spread of COVID-19 offers a way out for most countries that are stuck in lockdown and it also acts as a model response to faces the future outbreak of such diseases as well. From the experience of the MERS outbreak, the country learned the importance of diagnostic testing and basic infection prevention measures, which all came into play during the current pandemic. After the MERS outbreak, when KCDC was not able to trace the movements of the virus, South Korea changed the law allowing the government to collect a patient's data and security footage during an outbreak. All their steps are logged and then shared to alert people to stay away from the path of infection and if a confirmed case is found near a person's whereabouts, authorities send a text to let the person know if he or she has crossed paths with an infected person. While tracing people's every move can be controversial, many in South Korea prioritize public health over privacy in an outbreak. As a result, South Korea was able to test hundreds of thousands of people, more than any other country at the time, and this made it easier for authorities to track and contain the spread of the virus. This ability to find and treat infected people has allowed Korea to avoid aggressive lockdowns and helped to bend the curve of the outbreak that started out dangerously steep. With just 30 
cases reported, South Korean Health authorities had already started working with biotech companies to develop a test kit for the novel coronavirus, making available thousands of test kits. Because the government had already equipped hospitals with coronavirus tests, doctors were able to test (patients right away), and contact tracing, in which all people an infected patient has had contact with are traced and tested, helped break the chain of infections and prevent mass outbreaks. At this time, when almost every country is fighting against the same enemy, an invisible micro-pathogen. The success or failure of this fight will naturally be a measure of the overall capacity of a country and will have great implications for the global community and history. Through the key outcome reported in the study it is believed that a small but significant contribution could be made to the policy guidelines for the international community by sharing Korea's experiences and countermeasures against COVID-19 over the past six months. Although COVID-19 countermeasures taken by the South Korean government may not be conclusive or universal for all but its exemplary approach to COVID-19 can aid countries across the globe to strengthen their response system for the future outbreak of such contagious disease. For the successful resolution of COVID-19 spread, there is a need for a robust response system powered by the combination of state-of-art techniques and the public's voluntary cooperation along with the sharing of information transparently and promptly in society.

Acknowledgements No funding or sponsorship was received for this study or publication of this article.

\section{Compliance with ethical standards}

Conflict of interest The authors declare that they have no conflict of interest.

\section{References}

Bherwani, H., Nair, M., Musugu, K., et al. (2020). Valuation of air pollution externalities: Comparative assessment of economic damage and emission reduction under COVID-19 lockdown. Air Quality Atmosphere and Health, 13, 683-694.

Chan, J. F. W., Yuan, S., Kok, K. H., To, K. K. W., Chu, H., Yang, J., et al. (2020). A familial cluster of pneumonia associated with the 2019 novel coronavirus indicating person-to-person transmission: A study of a family cluster. The Lancet, 395(10223), 514-523.

Cucinotta, D., \& Vanelli, M. (2020). WHO declares COVID-19 a pandemic. Acta bio-medica: Atenei Parmensis, 91(1), 157-160.

De Wit, E., Van Doremalen, N., Falzarano, D., \& Munster, V. J. (2020). SARS and MERS: Recent insights into emerging coronaviruses. Nature Reviews Microbiology, 14, 523-34.

Gautam, S. (2020). COVID-19: Air pollution remains low as people stay at home. Air Quality Atmosphere and Health, 13, 853-857.

Gautam, S., \& Hens, L. (2020a). COVID-19: Impact by and on the environment, health and economy. Environment, Development and Sustainability, 22, 4953-4954.

Gautam, S., \& Hens, L. (2020b). SARS-CoV-2 pandemic in India: What might we expect? Environment, Development and Sustainability, 22, 3867-3869.

Gautam, S., \& Trivedi, U. (2020). Global implications of bio-aerosol in pandemic. Environment, Development and Sustainability, 22, 3861-3865.

Gorbalenya, A.E., Baker, S.C., Baric, R.S., et al. (2020). Severe acute respiratory syndrome-related coronavirus: The species and its viruses-a statement of the Coronavirus Study Group. bioRxiv preprint. https ://doi.org/10.1101/2020.02.07.937862

Hellewell, J., Abbott, S., Gimma, A., Bosse, N. I., Jarvis, C. I., Russell, T. W., et al. (2020). Feasibility of controlling COVID-19 outbreaks by isolation of cases and contacts. The Lancet Global Health, 8(4), 488-496.

JHGR, USA. (2020). John Hopkins GitHub repository on Coronavirus 2019, United Sates of America. https ://github.com/CSSEGISandData/COVID-19. Accessed May 30, 2020. 
KCDC, South Korea. (2020). Korea Centers for Disease Control and Prevention (KCDC). https://www.cdc. go.kr/cdc_eng/\#a. Accessed May 30, 2020.

Li, Q., Guan, X., Wu, P., Wang, X., Zhou, L., Tong, Y., et al. (2020). Early transmission dynamics in Wuhan, China, of novel coronavirus-infected pneumonia. The New England Journal of Medicine, 382, 1199-1207.

MOHW, South Korea. (2020). Ministry of Health and Welfare of South Korea (MOHW). https://ncov. mohw.go.kr/en. Accessed May 30, 2020.

Muhammad, S., Long, X., \& Salman, M. (2020). Covid - 19 pandemic and environmental pollution: a blessing in disguise? Science of the Total Environment, 728, 138820-138824.

Phelan, A. L., Katz, R., \& Gostin, L. O. (2020). The novel coronavirus originating in Wuhan, China: Challenges for Global Health Governance. JAMA, 323, 709-710.

Richman, D. D., Whitley, R. J., \& Hayden, F. G. (2016). Clinical virology (4th ed.). Washington: ASM Press.

Sarkodie, S. A., \& Owusu, P. A. (2020). Global assessment of environment, health and economic impact of the novel coronavirus (COVID-19). Environment, Development and Sustainability. https://doi. org/10.1007/s10668-020-00801-2.

Shim, E., Tariq, A., Choi, W., Lee, Y., \& Chowell, G. (2020). Transmission potential and severity of COVID-19 in South Korea. International Journal of Infectious Diseases, 193, 339-344.

Sun, N., Shi, S., Jiao, D., Song, R., Ma, L., Wang, H., et al. (2020). A qualitative study on the psychological experience of caregivers of COVID-19 patients. American Journal of Infection Control, 48, 592-298.

Wang, C., Horby, P. W., Hayden, F. G., \& Gao, G. F. (2020a). A novel coronavirus outbreak of global health concern. The Lancet, 395(10223), 470-473.

Wang, P., Chen, K., Zhu, S., Wang, P., \& Zhang, H. (2020b). Severe air pollution events not avoided by reduced anthropogenic activities during COVID-19 outbreak. Resources, Conservation and Recycling, $158,104814-104822$.

WHO. (2020a). Naming the coronavirus disease (COVID-19) and the virus that causes it. World Health Organization. https://www.who.int/emergencies/diseases/novel-coronavirus-2019/technical-guidance/. Accessed July 7, 2020.

WHO. (2020b). Q\&A on coronaviruses (COVID-19). https://www.who.int/emergencies/diseases/novel -coronavirus-2019/question-and-answers-hub/q-a-detail/q-a-coronaviruses. Accessed July 7, 2020.

WHO. (2020c). https://www.who.int/news-room/q-a-detail/q-a-coronaviruses. Accessed July 7, 2020.

Worldometer. (2020). Coronavirus worldometer on Coronavirus 2019. https://www.worldometers.info/coron avirus/. Accessed July 7, 2020.

Wu, F., Zhao, S., Yu, B., Chen, Y. M., Wang, W., Song, Z. G., et al. (2020). A new coronavirus associated with human respiratory disease in China. Nature, 579, 265-269.

Zhou, M., Zhang, X., \& Qu, J. (2020). Coronavirus disease 2019 (COVID-19): A clinical update. Frontiers in Medicine, 14, 126-135.

Zhou, P., Yang, X., Wang, X., et al. (2020). A pneumonia outbreak associated with a new coronavirus of probable bat origin. Nature, 579, 270-273.

Zhou, G., Chen, S., \& Chen, Z. (2020). Advances in COVID-19: the virus, the pathogenesis, and evidencebased control and therapeutic strategies. Frontiers in Medicine, 14, 117-125.

Publisher's Note Springer Nature remains neutral with regard to jurisdictional claims in published maps and institutional affiliations. 